\title{
The Airborne Demonstrator for the Direct-Detection Doppler Wind Lidar ALADIN on ADM-Aeolus. Part II: Simulations and Rayleigh Receiver Radiometric Performance
}

\author{
Ulrike PAFFrath, Christian Lemmerz, Oliver Reitebuch, AND BENJAMin Witschas \\ Deutsches Zentrum für Luft- und Raumfahrt, Institut für Physik der Atmosphäre, Oberpfaffenhofen, Germany
}

INES NIKOLAUS

Physics Solutions, Munich, Germany

VOLKER FREUDENTHALER

Ludwig-Maximilians-University of Munich, Munich, Germany

(Manuscript received 7 April 2009, in final form 21 July 2009)

\begin{abstract}
In the frame of the Atmospheric Dynamics Mission Aeolus (ADM-Aeolus) satellite mission by the European Space Agency (ESA), a prototype of a direct-detection Doppler wind lidar was developed to measure wind from ground and aircraft at $355 \mathrm{~nm}$. Wind is measured from aerosol backscatter signal with a Fizeau interferometer and from molecular backscatter signal with a Fabry-Perot interferometer. The aim of this study is to validate the satellite instrument before launch, improve the retrieval algorithms, and consolidate the expected performance. The detected backscatter signal intensities determine the instrument wind measurement performance among other factors, such as accuracy of the calibration and stability of the optical alignment. Results of measurements and simulations for a ground-based instrument are compared, analyzed, and discussed. The simulated atmospheric aerosol models were validated by use of an additional backscatter lidar. The measured Rayleigh backscatter signals of the wind lidar prototype up to an altitude of $17 \mathrm{~km}$ are compared to simulations and show a good agreement by a factor better than 2, including the analyses of different error sources. First analyses of the signal at the Mie receiver from high cirrus clouds are presented. In addition, the simulations of the Rayleigh signal intensities of the Atmospheric Laser Doppler Instrument (ALADIN) Airborne Demonstrator (A2D) instrument on ground and aircraft were compared to simulations of the satellite system. The satellite signal intensities above $11.5 \mathrm{~km}$ are larger than those from the A2D ground-based instrument and always smaller than those from the aircraft for all altitudes.
\end{abstract}

\section{Introduction}

At present, our information on the three-dimensional wind field over the Northern Hemisphere oceans, the tropics, and the Southern Hemisphere is incomplete because of insufficient measurement data. There are significant areas where measurements do not yield reliable data, and there is a strong demand for improvements in global wind profiles, which are crucial for numerical weather prediction and studies related to the global cli-

Corresponding author address: Oliver Reitebuch, Deutsches Zentrum für Luft- und Raumfahrt, Institut für Physik der Atmosphäre, Oberpfaffenhofen, 82234 Wessling, Germany.

E-mail: oliver.reitebuch@dlr.de mate (Baker et al. 1995; ESA 1999). Satellite-based lidar systems offer the potential for adequate vertical resolution and global coverage.

Within the context of the Earth Explorer core program of the European Space Agency (ESA), the Atmospheric Dynamics Mission Aeolus (ADM-Aeolus) comprises a direct-detection Doppler lidar to measure global wind fields from satellite, which will be the first European lidar in space and the first wind lidar in space worldwide. The lidar system on ADM-Aeolus is the Atmospheric Laser Doppler Lidar Instrument (ALADIN), which is designed to provide global observations of wind profiles in the troposphere and lower stratosphere for numerical weather prediction (ESA 2008; Stoffelen et al. 2005). 
In the frame of the ADM-Aeolus program, a prototype instrument was developed-the ALADIN Airborne Demonstrator (A2D) - to validate the measurement principle with realistic atmospheric signals from ground and aircraft before satellite launch. The instrument design of the A2D is described by Reitebuch et al. (2009, hereafter Part I).

To evaluate the measurement capability of the instrument and to predict its performance, the detected signal intensity was analyzed. The random error of wind measurements of the ALADIN instrument is mainly determined by the signal intensity resulting from photon noise. A simulator was developed to represent the ALADIN instrument for performance analyses and to improve the processing algorithms. The objective of this paper is to compare the expected signal intensities from simulations with measurements to validate the radiometric performance.

The radiometric performance of direct-detection Doppler lidars was determined by simulations, beginning in 1979, for different spaceborne instruments (Abreu 1979; Menzies 1986; Rees and McDermid 1990; McGill et al. 1999). The radiometric performance was validated for attenuated backscatter, as shown by Tao et al. (2008), for measurements of a ground-based instrument and the current satellite lidar on the Cloud-Aerosol Lidar and Infrared Pathfinder Satellite Observation (CALIPSO). A comparison of measured and modeled signal intensities was shown by Fischer et al. (1995) for a ground-based wind lidar, concluding that the measured radiometric signal intensities are within the range of the modeled values. A performance validation was presented by Gentry and Chen (2003) for a mobile wind lidar at a wavelength of $355 \mathrm{~nm}$, where simulations and measurements correspond to each other.

A lidar simulator was introduced by Veldman et al. (1999) to analyze the performance of the ADM-Aeolus instrument during its initial design phase (ESA 1999). It was further applied by Marseille and Stoffelen (2003) for the performance prediction regarding different atmospheric conditions. A simulator of the direct-detection lidar for the ADM-Aeolus instrument was developed by Leike et al. (2001) and updated to incorporate the actual ALADIN satellite design. This simulator provided the basis of the A2D simulator, which was used to validate the A2D instrument (Paffrath 2006).

Measurements with the A2D were performed in 2007 and 2008 from ground. It is planned to extend the analysis of the radiometric performance with measurements from aircraft in a downward-looking perspective, as for the ALADIN satellite. In this study, the radiometric performance of simulations and ground-based measurements is analyzed. Additionally, simulations of the A2D on ground and aircraft are compared to simulations of the satellite.

The A2D instrument is introduced in section 2. The simulator is presented in section 3, and results of the radiometric performance are discussed in section 4 .

\section{Instrument description}

The A2D includes a frequency-tripled Nd:YAG laser operating at a wavelength of $354.89 \mathrm{~nm}$ (Schröder et al. 2007), a Cassegrain telescope with a diameter of $0.2 \mathrm{~m}$, a coaxial laser beam path with respect to the telescope, and two spectrometers (Fig. 1) to detect the aerosol and molecular backscatter signal (Durand et al. 2005; Part I). Details of the A2D design and comparisons to the satellite instrument can be found in Part I.

The emitted photons of the laser pass the transmit optics with a transmission $\tau_{T}$, which includes three mirrors, and for the airborne systems, the aircraft window. The backscatter signal from the atmosphere is collected by the telescope, reflected by mirrors, and passes the front optics with a receive transmission $\tau_{R}$.

The backscatter signal is partly transmitted through the Fizeau interferometer and imaged as a fringe onto the detector. The signal strength depends on the wavelengthdependent transmission of the Fizeau interferometer $\tau_{\mathrm{Fiz}}(\lambda)$ and the peak transmission of 0.406 , which is described in section $3 \mathrm{e}$. This transmission $\tau_{\mathrm{Fiz}}(\lambda)$, when integrated over the imaged spectral range, yields the spectral efficiency of $12.7 \%$. Furthermore, a peak transmission of the Fizeau interferometer of $40.6 \%$ has to be taken into account. The aperture of the Fizeau interferometer is circular; because of the truncation at a square detector plane, the signal is reduced by a factor of $2 / \pi$, which is called the pupil truncation ratio (Paffrath 2006).

After reflection at the Fizeau interferometer, the backscatter signal is directed toward the Fabry-Perot interferometer. The Doppler frequency shift of the molecular backscatter signal is measured with the double-edge method using a Fabry-Perot interferometer (Garnier and Chanin 1992; Gentry et al. 2000), which is characterized by a new method to separate light depending on polarization called the sequential technique (Fig. 2).

In the sequential Fabry-Perot interferometer of the A2D with a mean spectral reflection of $82 \%$, the incoming photons are directed first to filter A with a resulting mean spectral transmission of about $18 \%$. Thus, $82 \%$ of the photons are reflected off the first filter to the second filter B, where again $18 \%$ of the incoming photons are transmitted, resulting in a total transmission of $15 \%$ to filter B. Such a scheme is more efficient than conventional nonsequential Fabry-Perot 


\section{Atmosphere}

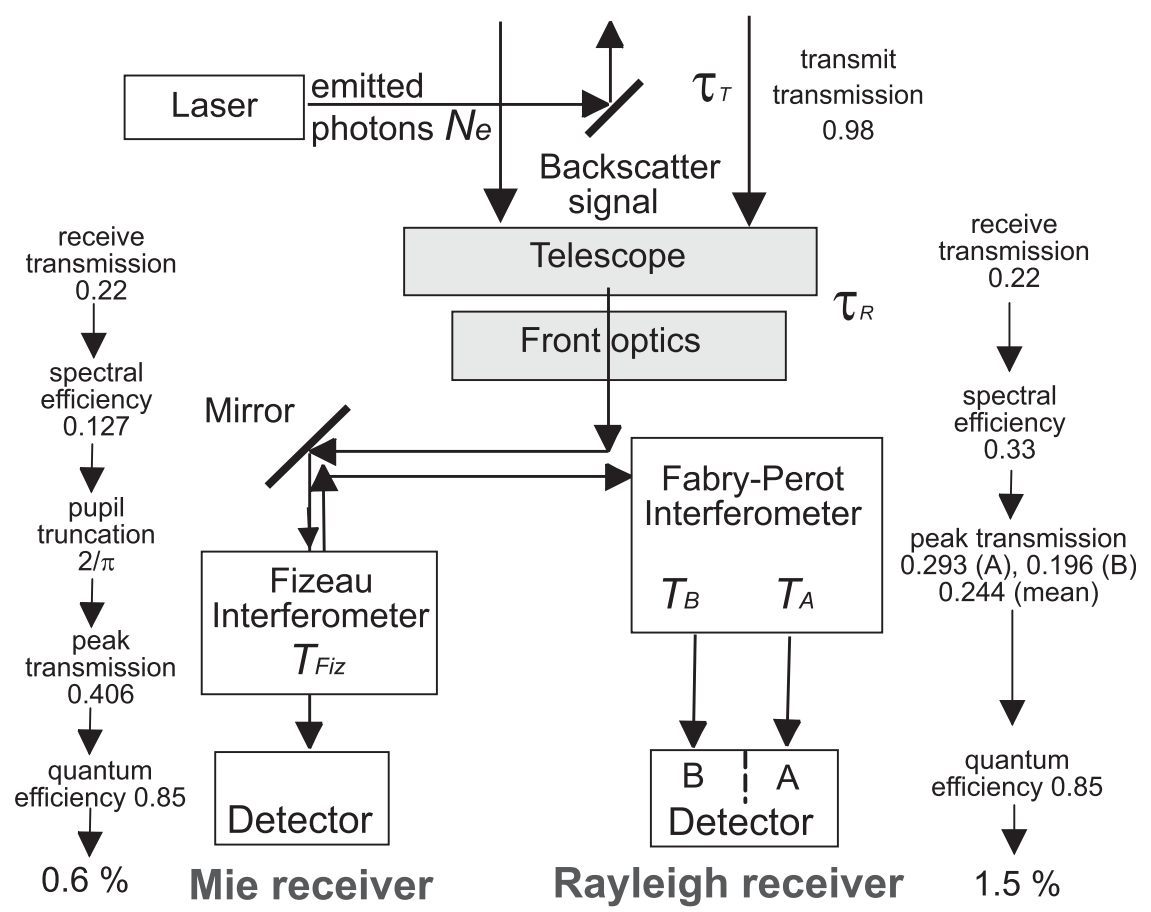

FIG. 1. Block diagram of the A2D receiver with the corresponding optical transmission coefficients used for simulations. The square detector plane of the Rayleigh receiver is divided into two sections for filters A and B. The efficiency of the Mie (Rayleigh) receiver is $0.6 \%(1.5 \%)$.

interferometers, where a beam splitter halves the incoming flux to each filter.

The sequential routing technique results in different peak transmissions for filters $\mathrm{A}$ and $\mathrm{B}$. The transmissions of both filters for zero wind speed and a Doppler-shifted spectrum for $250 \mathrm{~m} \mathrm{~s}^{-1}$ (the large value is taken for illustration) are shown in Fig. 3, where the Rayleigh spectrum with zero wind speed is centered close to the cross point of both filter curves. In the presence of wind speed, however, the Rayleigh spectrum is shifted toward one maximum of the filter curves, resulting in a difference of intensity ratio of the two filters. The Doppler shift can be determined from either the ratio of the intensities $A / B$ (Flesia and Korb 1999; Gentry et al. 2000) or from the contrast function $(A-B) /(A+B)$, as suggested by Chanin et al. (1989) and used for ALADIN (Dabas et al. 2008; Tan et al. 2008).

To analyze the radiometric performance, the signal intensities that are transmitted through filters $A$ and $B$ are summed up. This total signal is only slightly affected by the wind speed. Winds of $10 \mathrm{~m} \mathrm{~s}^{-1}$ along the line of sight lead to a shift of the Rayleigh spectrum of $0.02 \mathrm{pm}$ and therefore only lead to small variations in the total signal of $A$ and $B$ of less than $2 \%$. To validate the radiometric performance, the $\mathrm{A} 2 \mathrm{D}$ measurements from ground were performed with zenith-looking geometry, where only vertical winds affect the signal. The incoming photons in the Rayleigh receiver path are reduced by the filter peak transmission ( 0.293 of $A$ and 0.196 of $B$ ) and the spectral efficiency. The spectral efficiency of the

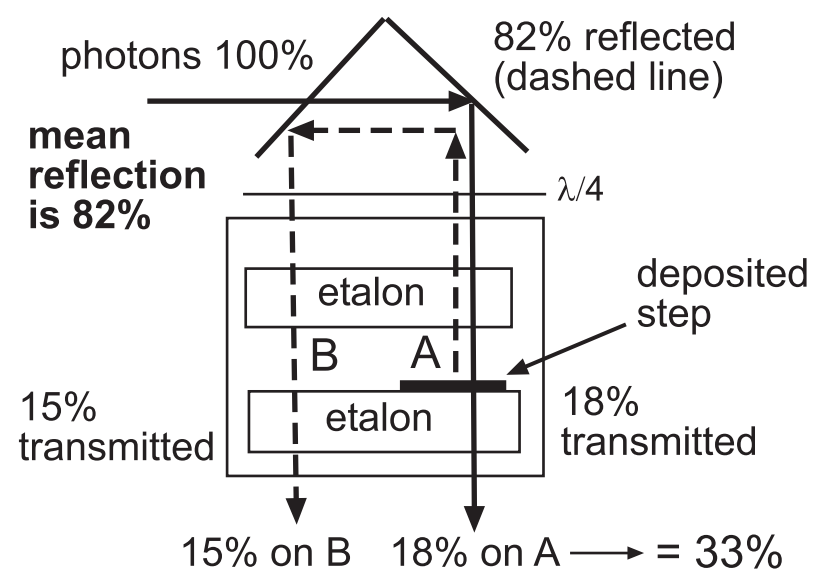

FIG. 2. Illustration of the spectral efficiency of the sequential Fabry-Perot interferometer for a mean reflection of $82 \%$ : the transmitted signal of filter A (B) with $18 \%$ (15\%) efficiency results in the total spectral efficiency of $33 \%$ for a broadband Rayleigh spectrum. 


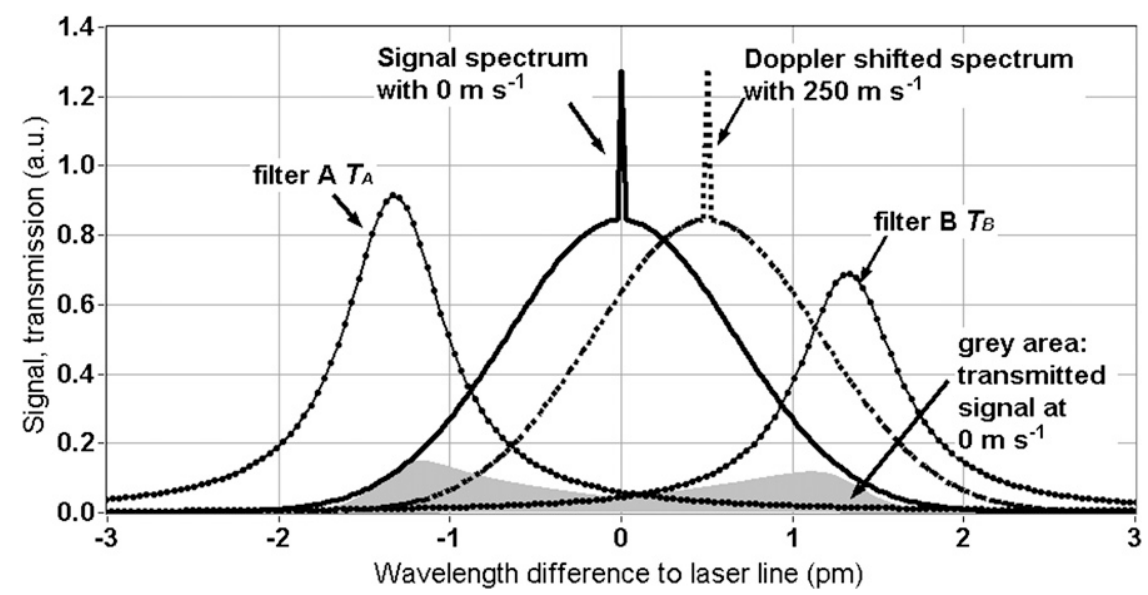

FIG. 3. Principle of the double-edge method with filters A and B and an atmospheric signal spectrum with the narrowband Mie and the broadband Rayleigh signal for 0 and $250 \mathrm{~m} \mathrm{~s}^{-1}$. Gray areas indicate the transmitted signal to the Rayleigh detector for $0 \mathrm{~m} \mathrm{~s}^{-1}$.

Fabry-Perot interferometer describes the ratio of transmitted to incoming photons and is determined by the spectral width of the Rayleigh signal, the filter spectral widths, and the filter spectral spacing. Altogether, the transmission factors of the Rayleigh receiver are the spectral efficiency (0.33), the peak transmission (mean 0.244), the receive optics transmission (0.22), and the quantum efficiency of the detector (0.85), and they result in a Rayleigh receiver efficiency of $1.5 \%$. The corresponding efficiency is $0.6 \%$ for the Mie receiver.

The instrument parameters of the A2D are listed in Table 1. The A2D detector is an accumulation charged coupled device (ACCD) that is capable of accumulating electronic charges from several laser-pulse returns. The incoming photons at the ACCD are converted to electrons with a quantum efficiency of 0.85 . The signal is imaged onto a light sensitive area of $16 \times 16$ pixels. An electro-optic modulator (EOM) in the front optics is used to reduce the backscatter light close to the instrument up to $1 \mathrm{~km}$ to avoid a saturation of the ACCD.

During measurements in 2007, the transmission of the EOM was reduced to 0.75 for all altitudes. However, the nominal transmission of $100 \%$ was achieved in 2008 .

\section{Simulations: Atmosphere and instrument}

The ALADIN prototype simulator was developed to represent the A2D operated on ground and aircraft. The simulator includes the laser transmitter, the receiver, the detection unit, and the interaction of the transmitted light with the atmosphere. This enables the study of the radiometric and wind measurement performance for different atmospheric states and the improvement of the wind retrieval algorithms. The sim- ulator is characterized by a high vertical atmospheric layer resolution of $15 \mathrm{~m}$. Simulations are performed with single or accumulated laser-pulse spectra with a Poissondistributed random number of detected photons from atmospheric scattering processes. The input parameters of the simulator are adapted to the actual instrumental parameters.

\section{a. Backscatter signal}

The lidar equation is used to determine the backscatter signal detected by a lidar system. The number of signal electrons on the detector per laser pulse from a distance $r$ from the lidar system is given by

$N_{e}(\lambda, r)=N_{L} \frac{\Delta R(A)}{r^{2}} \tau(\lambda) T_{p} \tau_{R} \tau_{T} \mu_{\mathrm{eff}} \beta(r) T^{2}(r)$,

where $A$ is the area of the receiver telescope; $\Delta R$ is the depth of the sensing volume; $\beta$ is the atmospheric backscatter coefficient; and $T^{2}$ is the atmospheric two-way transmission, including molecular and aerosol extinction. The instrumental parameters are the wavelengthdependent transmission $\tau(\lambda)$, the filter peak transmission $T_{p}\left(T_{A}, T_{B}\right.$, and $\left.T_{\mathrm{Fiz}}\right)$, the receive optics transmission $\tau_{R}$, the transmit optics transmission $\tau_{T}$, and the quantum efficiency $\mu_{\text {eff }}$ of the detector. The term $N_{L}$ is the equivalent number of emitted photons by the laser, which are derived from

$$
\mathrm{N}_{L}=\frac{\lambda_{L}}{h c} E_{L}
$$

where $\lambda_{L}$ is the wavelength of the laser, $c$ is the speed of light, $h$ is Planck's constant, and $E_{L}$ is the energy of the laser pulse (Table 1). 
TABLE 1. Instrument parameters of the A2D and the satellite instrument used for simulations.

\begin{tabular}{|c|c|c|c|c|}
\hline \multirow[b]{2}{*}{ Instrument } & \multirow[b]{2}{*}{ Symbol } & \multirow[b]{2}{*}{ Parameter } & \multicolumn{2}{|c|}{ Value in simulation } \\
\hline & & & $\mathrm{A} 2 \mathrm{D}$ & Satellite \\
\hline Instrument & $z_{i}$ & Altitude & $0 \mathrm{~km}$ & $408 \mathrm{~km}$ \\
\hline \multirow{5}{*}{ Laser } & $\lambda_{L}$ & Laser wavelength & $354.9 \mathrm{~nm}^{*}$ & $355 \mathrm{~nm}$ \\
\hline & $E_{L}$ & Laser pulse energy & $57 \mathrm{~mJ} *$ & $120 \mathrm{~mJ}$ \\
\hline & $\mathrm{FWHM}_{\mathrm{L}}$ & Laser line width & $0.021 \mathrm{pm}^{*}$ & $0.021 \mathrm{pm}$ \\
\hline & $\theta_{L}$ & Laser divergence & $200 \mu \operatorname{rad}(2007) *$ & $12 \mu \mathrm{rad}$ \\
\hline & & & $100 \mu \operatorname{rad}(2008) *$ & \\
\hline \multirow[t]{6}{*}{ Receiver } & $\theta_{R}$ & FOV & $100 \mu \mathrm{rad}$ & $19 \mu \mathrm{rad}$ \\
\hline & $d_{\mathrm{Tel}}$ & Telescope diameter & $0.2 \mathrm{~m}^{*}$ & $1.5 \mathrm{~m}$ \\
\hline & $\tau_{T}$ & Transmit optics transmission & $0.98 *$ & 0.66 \\
\hline & $\tau_{R}$ & Receive optics transmission & $0.22 *$ & 0.42 \\
\hline & $\tau_{\mathrm{EOM}}$ & EOM transmission & $0.75(2007)^{*}$ & 1.0 \\
\hline & & & $1.00(2008)^{*}$ & \\
\hline \multirow[t]{5}{*}{ Fizeau interferometer } & $T_{\mathrm{Fiz}}$ & Peak transmission & $0.406^{*}$ & 0.60 \\
\hline & & Spectral efficiency & $0.127 * *$ & 0.135 \\
\hline & & Filter FWHM & $0.059 \mathrm{pm}^{*}$ & $0.059 \mathrm{pm}$ \\
\hline & & Filter USR & $0.69 \mathrm{pm} *$ & $0.69 \mathrm{pm}$ \\
\hline & & Filter FSR & $0.92 \mathrm{pm}^{* *}$ & $0.92 \mathrm{pm}$ \\
\hline \multirow[t]{7}{*}{ Fabry-Perot interferometer } & $T_{A}$ & Peak transmission A & $0.293^{*}$ & 0.68 \\
\hline & $T_{B}$ & Peak transmission B & $0.196^{*}$ & 0.61 \\
\hline & & Spectral efficiency & $0.33^{* *}$ & 0.37 \\
\hline & & Filter FWHM A & $0.749 \mathrm{pm}^{*}$ & $0.70 \mathrm{pm}$ \\
\hline & & Filter FWHM B & $0.752 \mathrm{pm} *$ & $0.70 \mathrm{pm}$ \\
\hline & & Filter FSR & $4.6 \mathrm{pm}^{*}$ & $4.6 \mathrm{pm}$ \\
\hline & & Spectral spacing & $2.603 \mathrm{pm}^{*}$ & $2.300 \mathrm{pm}$ \\
\hline ACCD & $\mu_{\mathrm{eff}}$ & Quantum efficiency & $0.85^{*}$ & 0.85 \\
\hline
\end{tabular}

* Measured.

** Derived from calculations.

\section{b. The atmosphere}

The atmospheric backscatter and extinction coefficients are calculated from the reference model atmosphere (RMA) climatology data, which were derived from field campaigns before 1991 (Vaughan et al. 1995). These data were used for different satellite lidar simulations (Marseille and Stoffelen 2003; Di Girolamo et al. 2008; Ehret et al. 2008). The aerosol backscatter coefficients of the median model agree within an order of magnitude and better with aerosol measurements in Europe during the last few years (Wandinger 2003). The temperature and pressure profiles of this study were taken from the U.S. Standard Atmosphere, 1976, which represents an idealized state of the earth's atmosphere, referring to a period with moderate solar activity for various climatic conditions (Champion 1985). Optionally, temperature, pressure, cloud cover, backscatter coefficients, and wind profiles from observations can be used as input to the simulator.

The molecular backscatter coefficient is derived from the Rayleigh backscatter cross section per air molecule $\sigma_{\mathrm{Mol}}\left(=8.444 \times 10^{-32} \mathrm{~m}^{2} \mathrm{sr}^{-1}\right.$ at $355 \mathrm{~nm}$; Collis and Russell 1976) and the number of molecules $N_{\text {Mol }}$ per unit volume depending on altitude $z$, which is calculated from the atmospheric temperature $T(z)$ and pressure $p(z)$ profile,

$$
\beta_{\mathrm{Mol}}=\left[\frac{296 \mathrm{~K}}{T(z)}\right]\left[\frac{p(z)}{1.013 \times 10^{5} \mathrm{~Pa}}\right] N_{L} \sigma_{\mathrm{Mol}},
$$

with $N_{L}=2.479 \times 10^{25} \mathrm{~m}^{-3}$ molecules per volume, the Loschmidt's number referenced to a temperature of $296 \mathrm{~K}$, and a pressure of $1.013 \times 10^{5} \mathrm{~Pa}$.

The two-way transmission is derived from

$$
T^{2}(z)=\exp \left[-2 \int_{z_{i}}^{z_{t}} \alpha(z) d z\right],
$$

where the total extinction $\alpha$ is the sum of the aerosol extinction $\alpha_{A}$ and molecular extinction $\alpha_{\text {Mol. }}$ The altitude of the instrument is $z_{i}$, and the altitude of the atmospheric target is $z_{t}$.

The molecular extinction is calculated from $\alpha_{\mathrm{Mol}}=$ $\beta_{\mathrm{Mol}} 8 \pi / 3$. The aerosol extinction is derived from $\alpha_{A}=$ $50 \beta_{A}$, where the extinction-to-backscatter ratio or lidar ratio is assumed to be a constant value of $50 \mathrm{sr}$, which can be assumed as a mean for continental aerosol (Vaughan et al. 1995; Winker et al. 1996; Marseille and Stoffelen 2003). 


\section{c. Spectral distribution of the backscatter signal}

The spectra for scattering on aerosols and molecules are calculated in dependence on wavelength and atmospheric temperature. The spectrum of laser light is broadened for molecular scattering resulting from the molecular thermal motion, which may be described by a Gaussian line profile function with a standard deviation (SD) $\sigma_{R}$ of

$$
\sigma_{R}=\frac{2 \lambda_{L}}{c} \sqrt{\frac{k T N_{A}}{m_{\text {air }}}},
$$

where $m_{\text {air }}$ is the mean molecular air mass $\left(2.9 \times 10^{-2}\right.$ $\left.\mathrm{kg} \mathrm{mol}^{-1}\right), k$ is the Boltzmann constant, and $N_{A}$ is the Avogadro constant. The spectrum of laser light scattered by aerosols is assumed to be equal to the full width at half maximum (FWHM) of the laser-pulse spectrum $\mathrm{FWHM}_{\mathrm{L}}$ (see Table 1).

\section{d. Effect of the laser beam exceeding the receiver field of view}

If the laser beam divergence $\left(\theta_{L}=200 \mu \mathrm{rad}\right.$ in 2007 and $100 \mu \mathrm{rad}$ in 2008) given as a $\pm 3 \sigma$ value is larger than the field of view (FOV; $\theta_{R}=100 \mu \mathrm{rad}$ ) of the receiver, then the transmitted laser beam power is partially lost and the backscatter signal is reduced. The laser beam intensity distribution was determined to be Gaussian with low $M^{2}$ values of 1.9 in 2007 and 1.2 in 2008. The

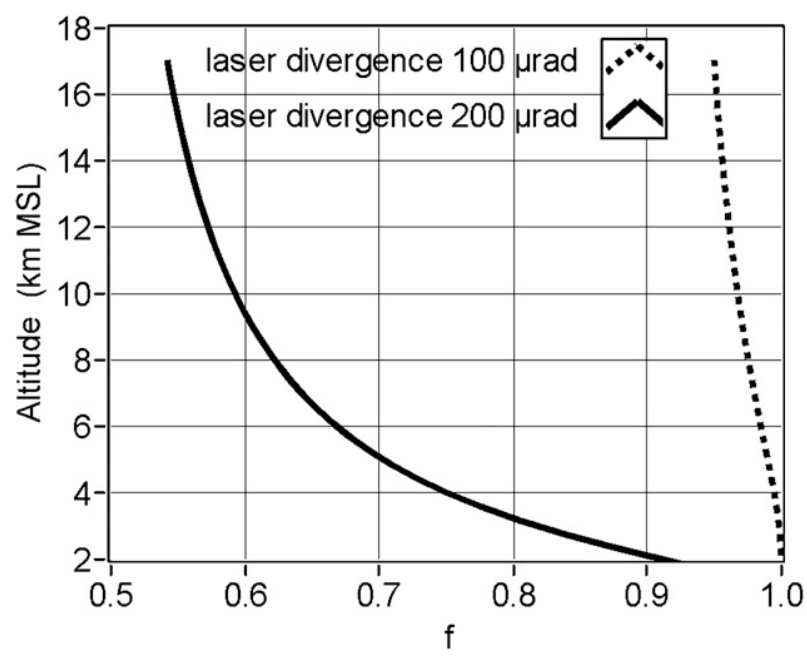

FIG. 4. The signal-loss factor $f(r)$ resulting from a laser divergence of 100 (dashed line) and $200 \mu \mathrm{rad}$ (bold line) for a receiver FOV of $100 \mu \mathrm{rad}$.

backscatter signal is reduced by a factor $f(r)$ depending on the range $r$, which is calculated from the ratio of the received power $P_{\text {rec }}$, restricted by the FOV of the receiver with radius $r_{\mathrm{FOV}}$, and the laser beam power $P_{\text {total }}$ with radius $r_{L}$ (Witschas 2007). The power of the laser beam is calculated by integration over the two-dimensional beam profile intensities in the two directions $x(r)$ and $y(r)$ :

$$
f(r)=\frac{P_{\mathrm{rec}}}{P_{\mathrm{total}}}=\frac{\int_{-r_{\mathrm{FOV}}}^{+r_{\mathrm{FOV}}} \int_{-r_{\mathrm{FOV}}}^{+r_{\mathrm{FOV}}} I_{0}(r) e\left\{-\left[\frac{9\left[x^{2}(r)+y^{2}(r)\right]}{2 r_{L}^{2}(r)}\right]\right\} d x d y}{\int_{-\infty}^{+\infty} \int_{-\infty}^{+\infty} I_{0}(r) e\left\{-\left[\frac{9\left[x^{2}(r)+y^{2}(r)\right]}{2 r_{L}^{2}(r)}\right]\right\} d x d y},
$$

where $I_{0}$ is the maximum laser intensity at distance $r$ and $r_{L}$ is the $3 \sigma$ radius of the laser beam, which is approximated by $r_{L}=0.5 \theta_{L} r$. The diameter of the FOV of the receiver can be calculated from $r_{\mathrm{FOV}}=0.5 \theta_{R} r+$ $r_{\mathrm{Tel}(r=0)}$. The function $f(r)$ is shown in Fig. 4 for a receiver FOV of $100 \mu \mathrm{rad}$ and laser divergences of 100 (dashed line) and $200 \mu \mathrm{rad}$ (bold line). Even with the laser beam within the FOV of the receiver, there is about $5 \%$ loss of backscatter light at the receiver from 14-km altitude because of the Gaussian beam profile. A laser divergence of $200 \mu \mathrm{rad}$ results in a loss of power of about $45 \%$ at $14-\mathrm{km}$ altitude.

\section{e. The Mie and Rayleigh spectrometer}

For the Mie receiver with the Fizeau interferometer, the filter transmission curves are assumed to be Airy functions. The Airy function is written as (Vaughan 2002)

$$
\tau(\lambda)=\left[1+F \sin ^{2}(\varphi / 2)\right]^{-1},
$$

where $F$ is the coefficient of the Finesse, which is derived from $F=\left(2 F_{r} / \pi\right)^{2}$ and the reflective finesse of $F_{r}=\mathrm{FSR} /$ FWHM. The free spectral range (FSR) is defined as the spectral distance of the transmission maxima with FSR = $\lambda^{2} /(2 n d)$ for perpendicular incidence of light (Vaughan 2002). The phase $\varphi=4 \pi n d(\cos \delta) \lambda^{-1}$ is linked to the wavelength, where $\delta$ is the angle of incidence, $d$ is the distance of the two etalon plates of the interferometer, and $n$ is the refractive index of the medium between the plates. The transmission of the Mie spectrometer depending on wavelength $\lambda$ is 


$$
\tau_{\text {Fiz }}(\lambda)=\left\{1+F \sin ^{2}\left[\frac{\pi(\cos \delta) \lambda}{\mathrm{FSR}_{\mathrm{Fiz}}}\right]\right\}^{-1},
$$

where $\mathrm{FSR}_{\mathrm{Fiz}}$ and $\mathrm{FWHM}_{\mathrm{Fiz}}$ are the free spectral range and full width at half maximum of the Fizeau interferometer, respectively, according to Table 1 . For the case where the laser beam is out of the FOV and the EOM transmission smaller than 1, the number of electrons at the Mie detector $N_{e, \text { Fiz }}$ is calculated by

$$
N_{e, \text { Fiz }}(\lambda, r)=N_{e}(\lambda, r) f(r) \tau_{\mathrm{EOM}},
$$

with $N_{e}(\lambda, r)$ from Eq. (1), the factor $f(r)$ [Eq. (6)], and the EOM transmission $\tau_{\text {EOM }}$ (Table 1$)$. The signal photons that are not transmitted through the Fizeau interferometer are reflected to the Rayleigh receiver $\left(N_{e, \mathrm{FP}}\right)$. The transmission of each filter of the FabryPerot interferometer can be described by the Airy function,

$$
\tau_{\mathrm{FP}}(\lambda)=\left\{1+F \sin ^{2}\left[\frac{\pi(\cos \delta) \lambda}{\mathrm{FSR}_{\mathrm{FP}}}\right]\right\}^{-1} .
$$

The number of electrons on the Rayleigh detector for filter A is calculated using Eqs. (1) and (10) with $f(r)$ and the EOM transmission $\tau_{\mathrm{EOM}}$ :

$$
N_{A}(\lambda, r)=N_{e, \mathrm{FP}}(\lambda, r) f(r) \tau_{\mathrm{EOM}} .
$$

The reflected signal of Rayleigh filter A is transmitted through filter $\mathrm{B}$, and the number of electrons on the Rayleigh detector for this filter is calculated with

$$
N_{B}(\lambda, r)=T_{B}(\lambda)\left[1-T_{A}(\lambda)\right] N_{A}(\lambda, r) .
$$

\section{Radiometric performance}

Ground-based measurements were performed in July 2007 at the Richard Aßmann Observatory of the German Weather Service (DWD; Deutscher Wetterdienst) in Lindenberg, $65 \mathrm{~km}$ southeast of Berlin $\left(52^{\circ} 13^{\prime} \mathrm{N}, 14^{\circ} 08^{\prime} \mathrm{E}\right.$, $97 \mathrm{~m} \mathrm{MSL}$ ) and in October 2008 at the German Aerospace Center (DLR; Deutsches Zentrum für Luft- und Raumfahrt) in Oberpfaffenhofen $\left(48^{\circ} 04^{\prime} \mathrm{N}, 11^{\circ} 16^{\prime} \mathrm{E}\right.$, $620 \mathrm{~m}$ MSL).

The main difference between the A2D measurements in 2007 and 2008 was the laser divergence, which was 200 $\mu \mathrm{rad}$ in 2007 and thus larger than the $100-\mu \mathrm{rad}$ field of view of the receiver, and the transmission of the EOM, which was $75 \%$ in 2007 (Table 1). In 2008, the laser beam divergence was $100 \mu \mathrm{rad}$, within the field of view of the receiver, and the EOM transmission was $100 \%$.

The measured signal electrons at the A2D detector arise from the laser light that is backscattered by the atmosphere, the background light during daytime operation, and an electronic detection chain offset. The detection chain offset is a constant electric voltage at the analog digital converter. The background light is reduced by several filters in the A2D front optic. The remaining background light and the detection chain offset are determined from an additional measurement and removed during signal processing.

To validate the Rayleigh radiometric performance, the signal electrons on the Rayleigh receiver were analyzed for cloud-free sky on different days with similar atmospheric temperature profiles. The measured Rayleigh signal level only depends slightly on atmospheric temperature. Furthermore, for higher altitudes, pure Rayleigh signal is expected at the receiver without impact of Mie signal. First analyses of the Mie signal at the Mie receiver are presented from higher cirrus clouds. Multipurpose lidar system (MULIS) measurements are available from 2007, and there was one event with cirrus clouds during the campaign. Further analyses are planned in the future.

Because of the impact of the telescope overlap up to $2 \mathrm{~km}$ and the attenuation of the signal close to the instrument resulting from the EOM, measurements and simulations were evaluated above $2-\mathrm{km}$ altitude. The range bins close to the instrument up to $2 \mathrm{~km}$ are $315.6 \mathrm{~m}$, and range bins for higher altitudes are from 631.2 to $1262.4 \mathrm{~m}$. The range bin width depends on the ACCD integration times $t_{\text {int }}$, which can be a multiple of $2.104 \mu \mathrm{s}(315.6 \mathrm{~m})$. During signal processing, the signal electrons at the Rayleigh receiver ACCD from filters A and $\mathrm{B}$ are summed up and scaled to a range bin width of $315.6 \mathrm{~m}$ by a factor of $t_{\mathrm{int}} / 2.104 \mu \mathrm{s}$ to have a uniform vertical resolution from measurements and simulations. The vertical signal profiles presented in this paper are the result of 630 accumulated laser pulses during $14 \mathrm{~s}$ at the detector. A total of $10 \%$ of 700 pulses from a laser with 50-Hz repetition rate are lost because of the ACCD read out. To validate the radiometric performance of the instrument, different days without clouds are compared.

Simulations of vertical profiles of signal electrons for different atmospheric conditions are introduced in section $4 a$. Section $4 b$ shows results of measured backscatter coefficients by an aerosol lidar compared with atmospheric models for aerosol content. A2D measurements from ground are validated with simulations in sections $4 \mathrm{c}$, $4 \mathrm{~d}$, and $4 \mathrm{e}$. Simulations of the A2D from ground and airborne platforms and the satellite instrument are shown in section $4 \mathrm{f}$.

\section{a. Simulations}

The signal electrons on the Rayleigh detector have been calculated for different aerosol content (median and lower-quartile models from the RMA; Fig. 6) and 


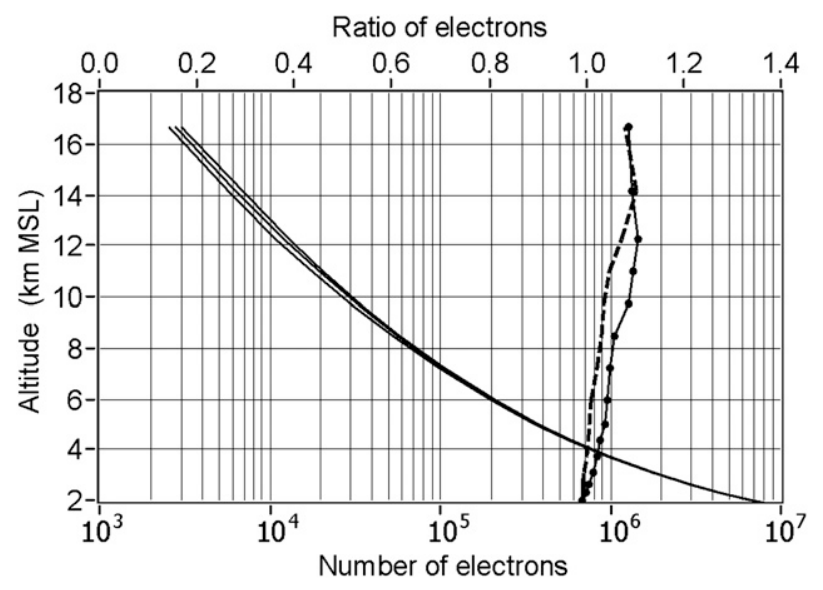

FIG. 5. Simulations of the number of signal electrons on the Rayleigh detector for different atmospheric temperature profiles (U.S. Standard Atmosphere, 1976; midlatitude summer; and arctic winter; thin black lines). The ratio of the number of electrons from the U.S. Standard Atmosphere, 1976 to the midlatitude summer (bold dashed line) and to arctic winter (dotted line) is up to a factor of 1.1 .

different atmospheric temperatures (U.S. Standard Atmosphere, 1976; midlatitude summer; and arctic winter; Fig. 5). Temperature and pressure determine the molecular density and thus the molecular backscatter signal [Eq. (3)].

The temperatures can vary over a large range, and the U.S. Standard Atmosphere, 1976 model is close to measured temperature profiles during the A2D observation period in July 2007 and October 2008. Two further temperature profiles have been considered: the arctic winter profile and the midlatitude summer profile with a maximum temperature difference of $30 \mathrm{~K}$ at an altitude of $10 \mathrm{~km}$, which results in a difference of a factor 1.1 of the Rayleigh signal (Fig. 5). The differences in signal from expected temperature differences during several measurement periods is about $5 \mathrm{~K}$, which results in a variation of signal of about $\pm 1 \%$ (Table 3 ).

The increased aerosol content in the boundary layer is a cause of higher extinction of laser light for lidar systems operating from ground, which leads to a decrease in signal from higher altitudes. The median aerosol model represents the atmosphere during most days in July 2007 quite well (section 4b). The Rayleigh signal in Fig. 6, with the median aerosol model (dotted line), shows lower signal from higher altitudes (e.g., $10 \mathrm{~km}$ ) resulting from extinction from aerosols in the boundary layer compared to the lower-quartile model (bold line). Days with lower aerosol content are represented by the lower-quartile model and show increased Rayleigh signal from higher altitudes (Fig. 6, bold line) resulting from the lower extinction in the boundary layer. Simulations of the median and lower-

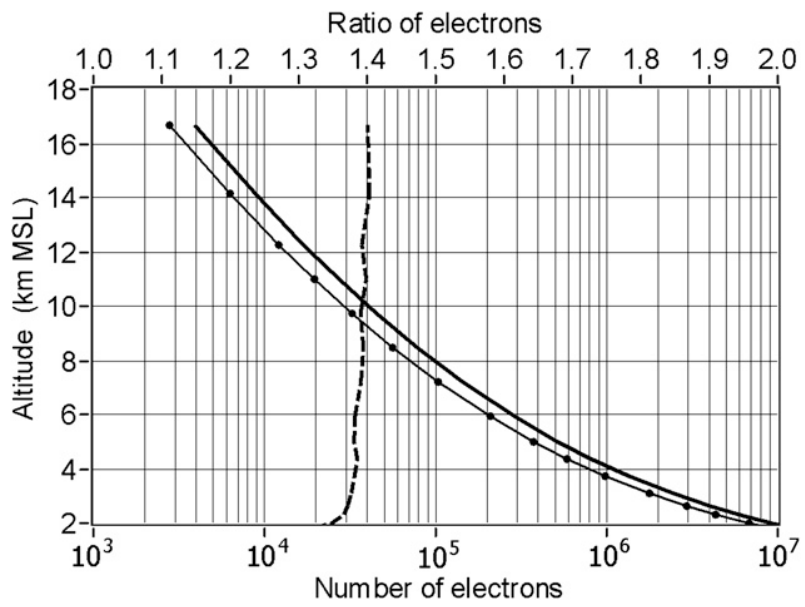

FIG. 6. Simulations of the number of signal electrons on the Rayleigh detector for the U.S. Standard Atmosphere, 1976 temperature profile and different aerosol models. The ratio of the number of electrons regarding the median (dotted line) and lowerquartile (bold line) aerosol models is up to a factor of 1.4 (dashed line).

quartile aerosol models with the temperature profile of the U.S. Standard Atmosphere, 1976 show differences in signal up to a factor of 1.4. The aerosol backscatter coefficients were determined from measurements by an aerosol backscatter lidar in 2007. There were no accompanying measurements of the backscatter coefficients in 2008. It is assumed that the differences of signal in 2008 presented in this paper, up to a factor $1.4(40 \%)$, can arise from differences in atmospheric aerosol content.

In addition, the aerosol content does not only decrease the Rayleigh signal by extinction above aerosol layers, but it also increase the Rayleigh receiver signals, which is called crosstalk, in the case of Mie backscatter signal from aerosols. From the Fizeau interferometer, about $5 \%$ of the incoming photons are transmitted (with a peak transmission of $40.6 \%$ and a spectral efficiency of 0.127; see Fig. 1) and $95 \%$ are reflected toward the Rayleigh receiver (section $3 \mathrm{e}$ ). Thus, the Rayleigh signal levels in the boundary layer with aerosols are significantly increased because of crosstalk of the Mie signal. In addition, the first $2 \mathrm{~km}$ are strongly influenced by the telescope overlap. In the following, analyses of the signal at the Rayleigh receiver were performed for cloudfree conditions above $2 \mathrm{~km}$. The signal at the Rayleigh receiver increase significantly by Mie signal from clouds; hence, only events with cloud-free sky are considered to determine the Rayleigh radiometric performance.

\section{b. MULIS measurements of aerosol backscatter coefficients}

The MULIS from the University of Munich is a mobile backscatter lidar with an Nd:YAG laser operating at 
three wavelengths $(1064,532$, and $355 \mathrm{~nm})$. The vertical profiles of the backscatter and extinction coefficients at $355 \mathrm{~nm}$ were derived from MULIS measurements (Freudenthaler et al. 2009) by means of the method described by Klett (1985), assuming a height-independent extinction-to-backscatter ratio of $55 \mathrm{sr}$. The volume and aerosol depolarization was measured at $532 \mathrm{~nm}$. For this study, the vertical profiles with a resolution of $7.5 \mathrm{~m}$ are averaged over $10 \mathrm{~min}$.

The comparisons of the aerosol backscatter models of the RMA and MULIS measurements during July 2007 (0628 and 1226 UTC 8 July; 0333, 0613, and 0849 UTC 14 July; 0750 UTC 15 July; and 1010 and 1830 UTC 17 July) is shown in Fig. 7, where the MULIS observations are indicated as thin black lines. All these measurements represent different aerosol loadings during periods without clouds. The mean value of all MULIS measurements is close to the RMA median aerosol model. Most of the MULIS measurements fall between the lower-quartile and the higher-quartile aerosol models, which vary by a factor of 10 in aerosol backscatter coefficient up to $2.5 \mathrm{~km}$. Although the aerosol backscatter coefficient of the median and lower-quartile models differs by a factor up to 5 , the effect on the Rayleigh signal is only a factor of 1.4 (Fig. 6).

\section{c. First results on the Mie radiometric performance}

The radiometric performance of the Mie receiver was not analyzed in detail up to now because of large variations in the backscatter signal arising from aerosol variations, depolarization, and specular reflectance from clouds or, in the case of a hard target, of unknown albedo. In a first step, a rough estimate of the Mie signal from cirrus clouds at $8-10-\mathrm{km}$ altitude was investigated and compared to MULIS measurements at 2008-2018 UTC 8 July. From MULIS measurements, a backscatter coefficient of $2 \times 10^{-5} \mathrm{~m}^{-1} \mathrm{sr}^{-1}$ and a lidar ratio of $13 \mathrm{sr}$ at $355 \mathrm{~nm}$ were retrieved. This corresponds quite well to the RMA model values for cirrus clouds with $1.4 \times$ $10^{-5} \mathrm{~m}^{-1} \mathrm{sr}^{-1}$ and $14 \mathrm{sr}$. The volume depolarization ratio varies between 0.1 and 0.3 at the cloud altitude derived from MULIS measurements. A mean depolarization ratio of 0.25 can be assumed for simulations for altitudes of $8-9 \mathrm{~km}$.

The summated number of 122000 Mie signal electrons with a cirrus cloud and a backscatter coefficient of the RMA is comparable to simulations with MULIS backscatter with 131000 signal electrons. The corresponding A2D zenith-pointing measurements result in 217000 Mie signal electrons from the cirrus cloud, which is a factor of 1.6 higher than from simulations with MULIS backscatter. During a $15^{\circ}$ off-zenith-pointing measurement (1955-1957 UTC), only 12250 signal

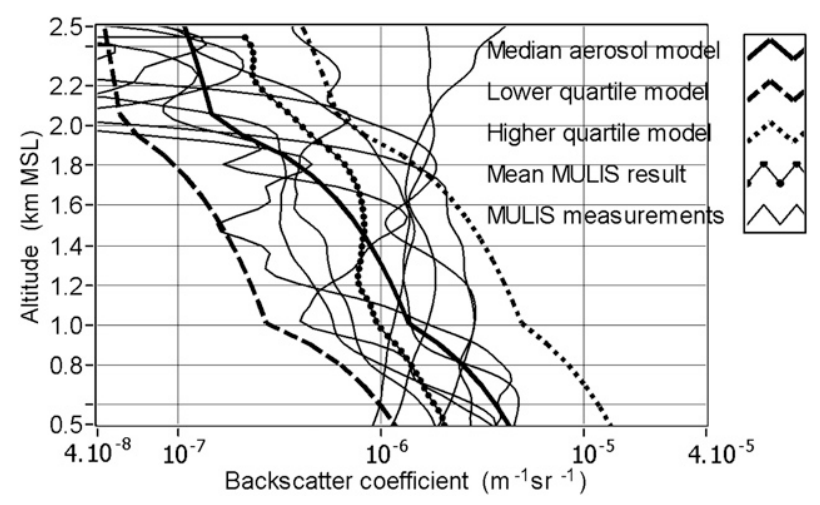

FIG. 7. Aerosol backscatter coefficient from MULIS measurements at $355 \mathrm{~nm}$ during different days in July 2007 (thin black lines). The mean aerosol backscatter coefficient of MULIS is represented by the dotted line. The RMA lower-quartile (dashed line on the left), RMA median (bold line), and RMA higher-quartile model atmosphere (short-dashed line on the right) are in good agreement with the MULIS measurements.

electrons at the Mie receiver were observed from a cirrus cloud at 9-km altitude, which is a factor of about 10 lower than from simulations. The high signal from the zenith-pointing measurement may arise from specular reflectance, which occurs for specific ice crystal orientations (Noel and Sassen 2005). To avoid specular reflectance, the MULIS lidar was pointing $2^{\circ}$ off zenith, but the A2D was pointing toward zenith to avoid impact of horizontal wind. A2D measurements with a $2^{\circ}-4^{\circ}$ offzenith-pointing system have to be performed to exclude specular reflectance.

Hard target measurements were performed with a surface of unknown albedo in a distance of 1-2 km, which is still in the telescope overlap range. Hence, these measurements were not considered with respect to the Mie radiometric performance. The reflectance of the sea surface from airborne observations with the A2D and the analysis of the Mie receiver signal are described by Li et al. (2010).

\section{d. Rayleigh radiometric performance of $A 2 D$ in 2007}

Measured A2D signal electrons from different days and simulations are compared in Fig. 8, where the Rayleigh backscatter signal is detected up to $17-\mathrm{km}$ altitude. The A2D measurements were selected for one day with lower aerosol content (14 July 2007) and another day with higher aerosol content (17 July 2007), as measured by MULIS. On 14 (17) July 2007, the A2D measurements were averaged over 5 (15) $\mathrm{min}$ and compared to simulations with the instrumental parameters from Table 1. Simulations were performed with measured MULIS aerosol backscatter coefficients 

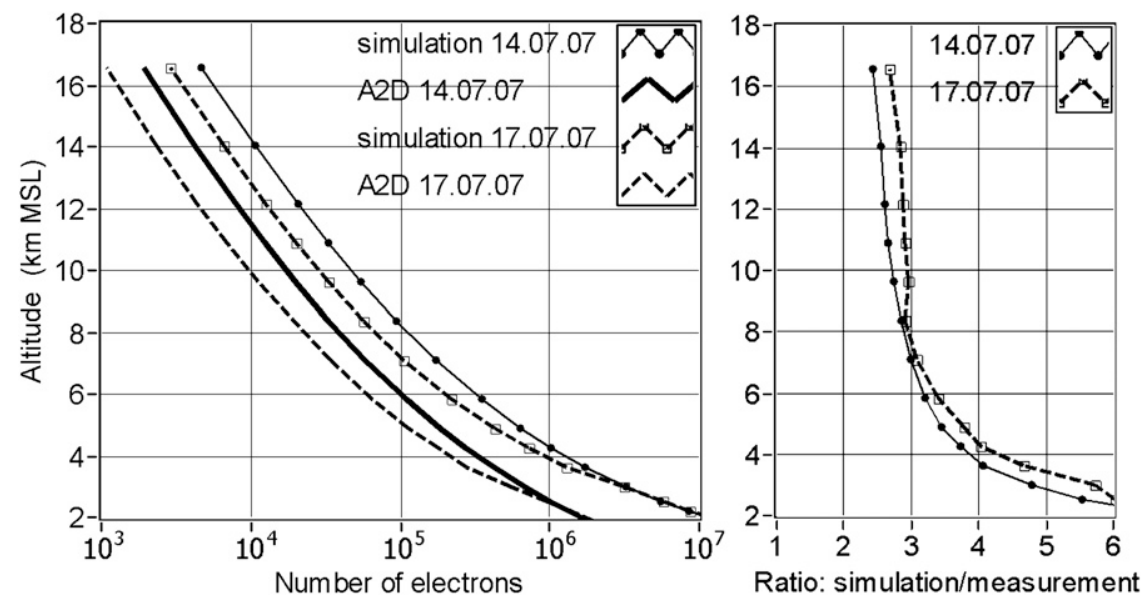

FIG. 8. (left) Signal electrons on the Rayleigh detector from A2D measurements on one day with lower aerosol content (14 Jul 2007; black bold line) and one day with higher aerosol content (17 Jul 2007; dashed bold line) are compared to simulations. Input parameters of simulations are measured temperatures by radiosonde with aerosol backscatter coefficients measured by MULIS (dotted lines). (right) The ratio of the number of simulated to measured electrons on the Rayleigh detector from 14 (black dotted line) and 17 Jul 2007 (dashed dotted line) are shown.

averaged over $10 \mathrm{~min}$ and temperature profiles from radiosonde, with the corresponding times in Table 2.

The A2D signal electrons measured on 14 and 17 July 2007 are a factor of 2.5-6 lower than the corresponding simulations (Fig. 8, right). Factors up to 6 at lower altitudes arise from broadening effects of the laser divergence resulting from atmospheric turbulence and small differences in alignment in the transmit and receive path from day to day. Both strongly affect the telescope overlap function (Wandinger and Ansmann 2002). Because of insufficient agreement of the simulated and observed overlap function, it has not been included in the simulations up to now. Small differences between both days are caused by differences in alignment of the transmit and receive path optics in 2007.

\section{e. Rayleigh radiometric performance of A2D in 2008}

In 2008, the laser divergence was reduced to be below $100 \mu \mathrm{rad}( \pm 3 \sigma, 99.7 \%)$ and is therefore within the receiver FOV. The EOM refractive index fluid was refilled, which leads to a nominal transmission of $100 \%$. Vertical profiles of the number of signal electrons on 12 and 20 October 2008 are all upon each other (Fig. 9), showing that the day-to-day variation of the alignment was also significantly improved.

Simulations using the median aerosol backscatter coefficient and the temperature of the U.S. Standard Atmosphere, 1976, as compared to A2D measurements, differ by a factor of about 2 for altitudes above $4 \mathrm{~km}$ (Fig. 9, right). A factor of up to 4 difference for altitudes below $4 \mathrm{~km}$ arises from broadening effects of the laser divergence resulting from atmospheric turbulence and small misalignments in the transmit and receive path. The fluctuations in signal are not larger than $3.5 \%$, which is the SD of the current measurement at 1040-1103 UTC 20 October 2008. Concluding, it was shown that measurements with the A2D differ to simulations in 2007 by a factor of 2.5 and in 2008 by a factor of 2.0 for altitudes above $4 \mathrm{~km}$.

The systematic differences of measurements and simulations arise from uncertainties of the atmospheric conditions and the instrument parameters. Error contributions to the measurements are the variation in alignment of the transmit and receive path and the turbulent broadening of the laser beam. Atmospheric turbulence can cause the laser beam to be broadened and

TABLE 2. Timetable of measurements from A2D, MULIS, and radiosonde.

\begin{tabular}{lll}
\hline \multicolumn{1}{c}{ Date } & \multicolumn{1}{c}{ A2D measurements } & \multicolumn{1}{c}{ Input simulations } \\
\hline 14 Jul 2007 & $0413-0418$ UTC & Radiosonde 0600 UTC; MULIS 0328-0338 UTC \\
17 Jul 2007 & $0708-0723$ UTC & Radiosonde 1200 UTC; MULIS 1010-1020 UTC \\
12 Oct 2008 & 1) 0903-1000 and 2) 1138-1146 UTC & U.S. Standard Atmosphere, 1976 RMA median aerosol model \\
20 Oct 2008 & 1040-1103 UTC & U.S. Standard Atmosphere, 1976 RMA median aerosol model \\
\hline
\end{tabular}



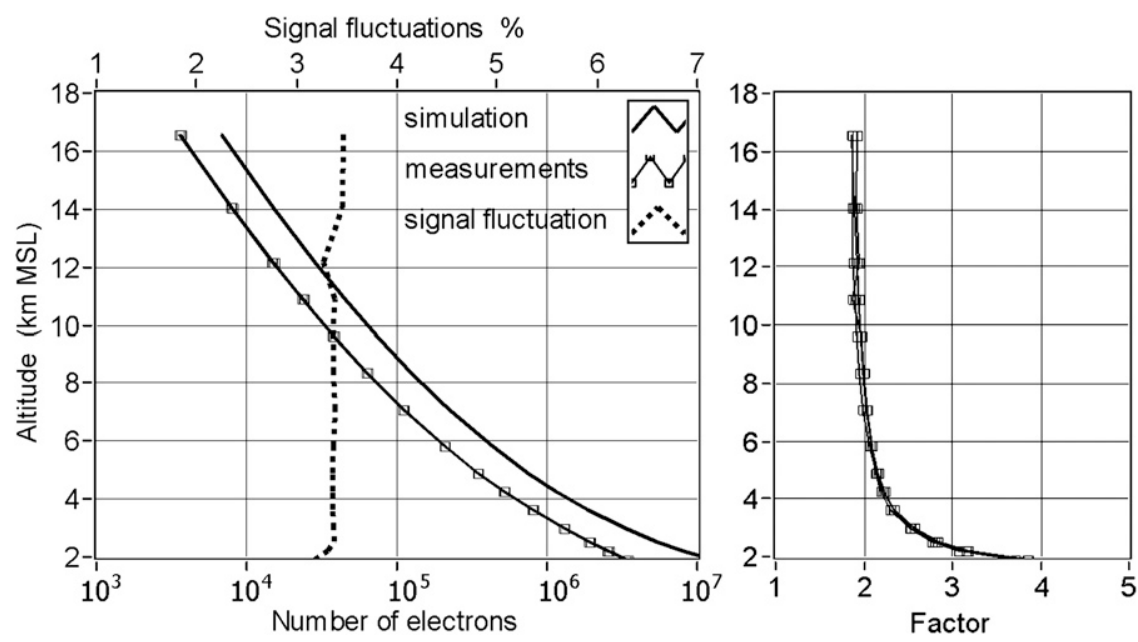

FIG. 9. (left) Signal electrons on the Rayleigh detector from A2D measurements on 12 Oct and 20 Oct 2008 (dotted lines) are placed upon each other. The signal fluctuations during $1 \mathrm{~h}$ on 12 Oct 2008 are below $3.5 \%$ (dashed line). The simulations were performed with the median aerosol model and temperature from the U.S. Standard Atmosphere, 1976 (bold line). (right) The ratios of the number of simulated to measured electrons on the Rayleigh detector are shown.

partially leave the FOV of the receiver. This was observed during time periods of $1 \mathrm{~h}$ (Fig. 9), and the resulting variations in signal are up to $3.5 \%$ (SD). Other influences are the uncertainties from the determination of the detection chain offset and the background light. The standard deviation of the background light and the detection chain offset is on the order of $\pm 6 \%$ (Table 3 ).

The variations in aerosol content contribute to the simulations, influencing the aerosol extinction and the transmission of the optics, which could be degraded or contaminated with dust. The degradation of the optics is assumed to be around $-10 \%$ for the receive path, the transmit path, and the front optics and $-10 \%$ for the quantum efficiency of the ACCD, because most of the parameters were characterized in 2003. The total degradation in Table 3 is calculated from the fourtimes-reduced transmission of $0.9^{4}$, which results in a value of degradation of $-34 \%$. The atmospheric variations resulting from aerosol extinction can vary up to $\pm 40 \%$ (Fig. 6 ) and up to $\pm 1 \%$ because of changes in temperature (Fig. 5). In Fig. 10, the numbers of signal electrons are shown with error bars for simulations and measurements on 20 October 2008. The total variations in signal of measurements result in error bars of $\pm 9.5 \%$, which are slightly visible in Fig. 10 on the bold black line. The simulated vertical profile of the number of signal electrons in this illustration is reduced by the optics degradation, and the error bars represent the atmospheric variations of $\pm 41 \%$. The error bars of simulations (gray) overlap the measured signal profiles.
Simulations including the optics degradation $(-34 \%)$ and using the median aerosol model and the U.S. Standard Atmosphere, 1976 (Fig. 10, left) compared to measurements differ by a factor of 1.2-2 (Fig. 10, right) and a factor of 1.5 for altitudes above $4 \mathrm{~km}$. Error sources arising from alignment, detection chain offset, and background light are probable. They were determined from a mean value over several measurement periods. The variation in atmospheric aerosol content in 2008 was derived from measurements in 2007. The optics degradation of the instrument over 4-5 yr is assumed probable.

\section{f. Signal intensities of measurements from ground, aircraft, and satellite}

The A2D instrument was designed to validate the satellite instrument principle and the performance model.

TABLE 3. Contributors to signal variations.

\begin{tabular}{lcc}
\hline \hline & \multicolumn{1}{c}{ Contributor } & Value \\
\hline Simulation & - Temperature: 5 K & $\pm 1 \%$ \\
atmosphere & - Aerosol: different days & $\pm 40 \%$ \\
& Total variation atmosphere & $\pm 41 \%$ \\
Simulation & - Transmit optics & $-10 \%$ \\
instrument & - Receive optics & $-10 \%$ \\
& - Spectrometer & $-10 \%$ \\
& - ACCD & $-10 \%$ \\
Measurement & Total optics degradation & $-34 \%$ \\
& - Alignment & $\pm 3.5 \%$ \\
& - Background light and & $\pm 6 \%$ \\
& detection chain offset & \\
& Total variation & $\pm 9.5 \%$ \\
\hline
\end{tabular}




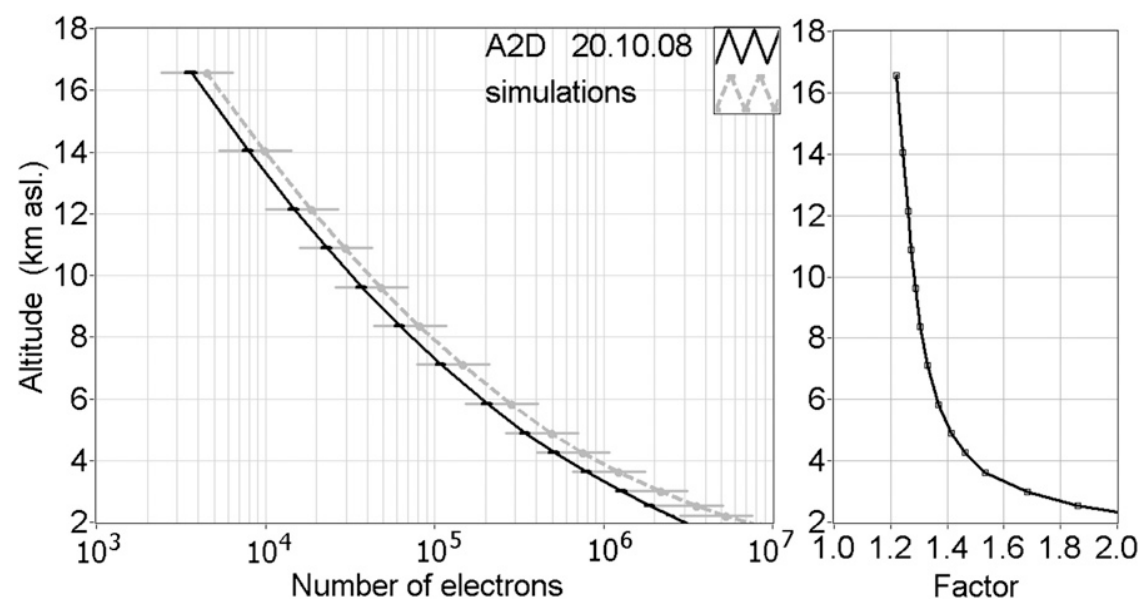

FIG. 10. (left) Number of signal electrons on the Rayleigh detector from A2D measurements on 20 Oct 2008 (black line) with error bars from alignment, detection chain offset, and background variations. Simulations including the optics degradation (gray line) with error bars showing the atmospheric variations. (right) The ratios of simulations including the optics degradation and measurements are shown.

Thus, simulations were performed (Fig. 11) for the A2D on ground (0 km MSL), on aircraft (8-km flight altitude), and for the satellite instrument (408-km altitude). The satellite and the airborne system are simulated with nadir pointing and the ground system with zenith pointing. The signals are calculated for 315.6-m range bin widths for all instruments. The different instrumental parameters of the A2D and the satellite (Part I) are taken from Table 1.

The main differences of the $\mathrm{A} 2 \mathrm{D}$ and the satellite regarding the radiometric performance are the optical efficiency of the instrument (section 2) and the rangecorrected energy aperture product $\left(E_{L} d_{\mathrm{tel}}^{2} R^{-2}\right)$. The optical efficiency of the Rayleigh receiver is $1.5 \%$ for the A2D and $5.4 \%$ for the satellite. The range-corrected energy aperture product at an altitude of $10 \mathrm{~km}$ of the A2D is a factor of 13.4 larger with regard to the satellite in case all instruments are nadir pointing. This is due to the telescope diameter of the satellite, which is 7.5 times larger $(1.5 \mathrm{~m}$ versus $0.2 \mathrm{~m})$, and the laser energy, which is about 2 times larger $(120 \mathrm{~mJ}$ versus $57 \mathrm{~mJ})$, compared to the A2D. The range of the A2D is $10 \mathrm{~km}$ and $408 \mathrm{~km}$ for the satellite for a measurement altitude of $10 \mathrm{~km}$.

The ground- and airborne-detected Rayleigh signal is mostly affected by the $1 / R^{2}$ dependency, which is indicated by high signal near the instrument and a strong intensity decrease for larger ranges. The Rayleigh signal detected by the satellite is nearly constant for the different atmospheric altitudes as a consequence of the range of about $408 \mathrm{~km}$ for the satellite. For the ground and airborne instrument, the impact of the telescope overlap is visible as a clear decrease of intensity close to the instrument at ranges below $1 \mathrm{~km}$. The higher signal intensities of the satellite at an altitude of $0 \mathrm{~km}$ arise from the ground reflectance.

The Rayleigh signal of the satellite instrument is comparable to the A2D operated on ground at an altitude of $11.5 \mathrm{~km}$. The intensities of simulations from the A2D operated on aircraft at a flight altitude of $8 \mathrm{~km}$ are higher than those from the satellite instrument for all altitudes. As a consequence, the wind measurement performance of the A2D operated on an airborne platform should be better than the satellite instrument at all altitudes.

For shot-noise limited detection, an LOS random wind error of $1.3 \mathrm{~m} \mathrm{~s}^{-1}$ is expected from 63500 electrons at

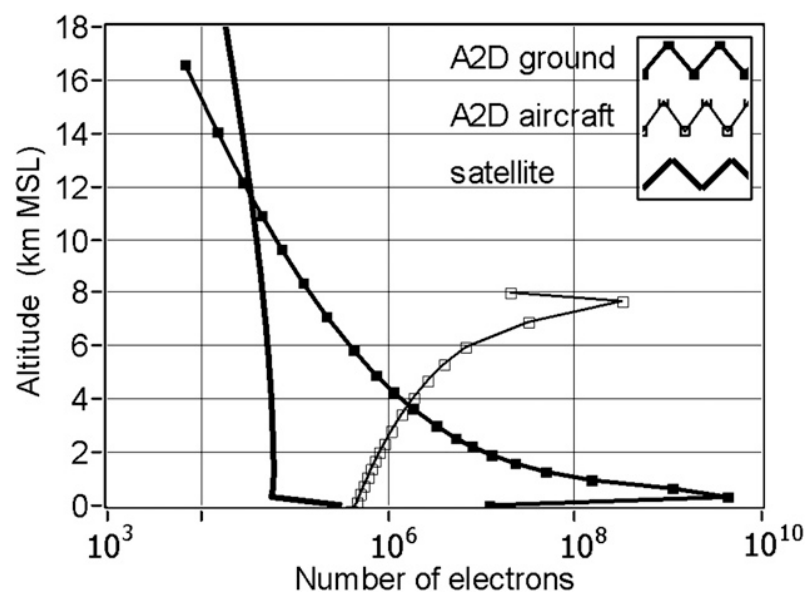

FIG. 11. Simulations of the number of signal electrons at the Rayleigh detector of the satellite instrument and the A2D ground and airborne system. All instruments are nadir/zenith pointing for comparison using the median aerosol model and the temperature of the U.S. Standard Atmosphere, 1976. 
TABLE 4. Overview of measurement and simulation results. The signal ratio is calculated from the ratio of simulations to measurements, where $T_{\text {RaSo }}$ is the temperature profile from radiosonde; $\beta_{\text {MULIS }}$ is the aerosol backscatter profile from MULIS; $T_{\text {stand }}$ is temperature profile of the U.S. Standard Atmosphere, 1976; and $\beta_{\mathrm{med}}$ is the aerosol backscatter profile from the median RMA.

\begin{tabular}{|c|c|c|c|c|}
\hline \multirow[b]{2}{*}{ Days } & \multicolumn{2}{|c|}{ Simulation input parameters } & \multicolumn{2}{|c|}{ Signal ratio } \\
\hline & Atm: & Instrument: & $\begin{array}{l}\text { Low alts } \\
2-4 \mathrm{~km}\end{array}$ & $\begin{array}{c}\text { High alts } \\
4-17 \mathrm{~km}\end{array}$ \\
\hline 14 and $17 \mathrm{Jul} 2007$ & $T_{\text {RaSo }}, \beta_{\text {MULIS }}$ & $\theta_{L}=200 \mu \mathrm{rad}, \tau_{E O M} 75 \%$ & $4-6$ & $2.5-4$ \\
\hline 12 and 20 Oct 2008 & $T_{\text {stand }}, \beta_{\text {med }}$ & Full performance & $2-4$ & 2 \\
\hline 12 and 20 Oct 2008 & $T_{\text {stand }}, \beta_{\text {med }}$ & Optics degradation $-34 \%$ & $1.5-2$ & $1.2-1.5$ \\
\hline 12 and 20 Oct 2008 & $T_{\text {stand }}, \beta_{\text {med }} \pm 40.5 \%$ & Optics degradation $-34 \%$ & 1 & 1 \\
\hline
\end{tabular}

the Rayleigh receiver at $8 \mathrm{~km}$ (Fig. 9) calculated with a sensitivity of $0.055 \% \mathrm{MHz}^{-1}$. With regard to the satellite and the A2D, there are about 34200 electrons from 11.5-km altitude (Fig. 11), which results in a random error of $1.7 \mathrm{~m} \mathrm{~s}^{-1}$ LOS. The wind measurement performance will be investigated in more detail using comparisons with wind profiler radar, radiosonde, and $2-\mu \mathrm{m}$ wind lidar observations.

\section{Summary}

The radiometric performance of the direct-detection Doppler wind lidar A2D is validated by comparisons of measured and simulated signal electrons at the Rayleigh receiver.

The signals depend on the instrument and atmospheric parameters. It was shown that the models of atmospheric aerosol content in the simulator compare well with the measurements of the backscatter coefficient over a European continental site by a backscatter lidar. Measurements during days with lower aerosol content correspond to the lower-quartile model atmosphere, and days with higher aerosol content are in between the median and the higher-quartile models. Both models are used for satellite instrument performance predictions.

Table 4 summarizes the Rayleigh radiometric performance results. The number of simulated signal electrons at the Rayleigh receiver differs from measurements by a factor of 2.5-4 in 2007 and by a factor of 2.0 in 2008 for altitudes from 4 to $17 \mathrm{~km}$. The simulations were performed with the current parameters of the instrument and the standard atmospheric models. The uncertainties in these factors arise partially from the variations in alignment $( \pm 3.5 \%$ during $1 \mathrm{~h})$, the degradation of the optical elements $(-34 \%)$, and the variations of atmospheric temperature and aerosol content $( \pm 41 \%)$. Taking this into account, the measurements of 2008 are clearly within the range of the expected error contributors. Simulations and measurements from 2008 agree better by a factor of 1.2-1.5 for altitudes above $4 \mathrm{~km}$.
The signal differences between measurements and simulations closer to the instrument $(2-4 \mathrm{~km})$ by a factor up to 6 arise from broadening effects of the laser divergence resulting from atmospheric turbulence and differences in alignment in the transmit and receiver path from day to day, which strongly affect the telescope overlap function. First analyses of the signal at the Mie receiver from clouds are presented. Mie signal electrons from a cirrus cloud from measurements with a $15^{\circ}$ offzenith pointing are about a factor of 10 lower than signals from simulations. Mie signal electrons from a zenithpointing measurement are higher than simulations by a factor of 1.6, which may arise from the impact of specular reflectance. Further investigations of the Mie receiver radiometric performance are planned for aerosol and cloud signals and the amount of Rayleigh signal on the Mie receiver.

Simulations of the A2D operated from ground and airborne platforms were compared to the satellite instrument. The satellite signals above $11.5 \mathrm{~km}$ are larger than those from A2D measurements from ground and always smaller than those from aircraft for all altitudes. Because of the signal dynamic range with $R^{-2}$, the signals decrease strongly with altitude for an instrument on ground but are rather constant with altitude for the satellite.

This study introduces a method to compare measured signals with simulations and to predict the instrument performance from the aircraft as well as from the satellite. This is a precondition to validate the satellite ALADIN instrument with respect to its future wind measurement performance. Other factors influencing the performance and its stability over its lifetime are the calibration of the Rayleigh and Mie receiver spectral response, which is determined by the stability of the filter spectral transmission and the optical alignment of the instrument.

Acknowledgments. The authors thank Martin Endemann, Olivier LeRille, Herbert Nett, and AnneGrete Straume from ESA for their useful contributions, 
and we wish to acknowledge M. Vaughan for his valuable and inspiring comments. We thank the support of the staff of the DWD (Deutscher Wetterdienst), in particular Dirk Engelbart and Volker Lehmann. Acknowledgements go to Markus Eifried, Silke Gross, Franziska Schnell, and Matthias Wiegner from the Department of Meteorology of the University of Munich. We thank Engelbert Nagel from DLR for his technical support.

\section{REFERENCES}

Abreu, V. J., 1979: Wind measurements from an orbital platform using a lidar system with incoherent detection: An analysis. Appl. Opt., 18, 2992-2997.

Baker, W. E., and Coauthors, 1995: Lidar-measured winds from space: A key component for weather and climate prediction. Bull. Amer. Meteor. Soc., 76, 869-888.

Champion, K. S. W., 1985: Standard and reference atmospheres. Handbook of Geophysics and the Space Environment, A. S. Jursa, Ed., United States Air Force Geophysics Laboratory, 14-1-14-43.

Chanin, M. L., A. Garnier, A. Hauchecorne, and J. Porteneuve, 1989: A Doppler lidar for measuring winds in the middle atmosphere. Geophys. Res. Lett., 16, 1273-1276.

Collis, R. T. H., and P. B. Russell, 1976: Lidar measurement of particles and gases by elastic backscattering and differential absorption. Laser Monitoring of the Atmosphere, Topics in Applied Science, Vol. 14, Springer Verlag, 70-152.

Dabas, A., M. L. Denneulin, P. Flamant, C. Loth, A. Garnier, and A. Dolfi-Bouteyre, 2008: Correcting winds measured with a Rayleigh Doppler lidar from pressure and temperature effects. Tellus, 60A, 206-215.

Di Girolamo, P., A. Behrendt, C. Kiemle, V. Wulfmeyer, H. Bauer, D. Summa, A. Dörnbrack, and G. Ehret, 2008: Simulation of satellite water vapour lidar measurements: Performance assessment under real atmospheric conditions. Remote Sens. Environ., 112, 1552-1568.

Durand, Y., R. Meynart, M. Endemann, E. Chinal, D. Morancais, T. Schröder, and O. Reitebuch, 2005: Manufacturing of an airborne demonstrator of ALADIN: The direct detection Doppler wind lidar for ADM-Aeolus. Lidar Technologies, Techniques, and Measurements for Atmospheric Remote Sensing, U. N. Singh, Ed., International Society for Optical Engineering (SPIE Proceedings, Vol. 5984), doi:10.1117/ 12.627789 .

Ehret, G., C. Kiemle, M. Wirth, A. Amediek, A. Fix, and S. Houweling, 2008: Space-borne remote sensing of $\mathrm{CO}_{2}, \mathrm{CH}_{4}$, and $\mathrm{N}_{2} \mathrm{O}$ by integrated path differential absorption lidar: $\mathrm{A}$ sensitivity analysis. Appl. Phys. B, 90, 593-608.

ESA, 1999: The four candidate Earth Explorer core missions: 4. Atmospheric Dynamics Mission. ESA SP-1233(4), 157 pp.

-, 2008: ADM-Aeolus Science Report, ESA Rep. SP-1311, $121 \mathrm{pp}$.

Fischer, K. W., V. J. Abreu, W. R. Skinner, J. E. Barnes, M. J. McGill, and T. D. Irgang, 1995: Visible wavelength Doppler lidar for measurement of wind and aerosol profiles during day and night. Opt. Eng., 34, 499-511.

Flesia, C., and C. L. Korb, 1999: Theory of the double-edge molecular technique for Doppler lidar wind measurement. Appl. Opt., 38, 432-440.
Freudenthaler, V., and Coauthors, 2009: Depolarization ratio profiling at several wavelengths in pure Saharan dust during SAMUM 2006. Tellus, 61B, 165-179.

Garnier, A., and M. L. Chanin, 1992: Description of a Doppler Rayleigh LIDAR for measuring wind in the middle atmosphere. Appl. Phys., 55B, 35-40.

Gentry, B. M., and H. Chen, 2003: Performance validation and error analysis for a direct detection molecular Doppler lidar. Lidar Remote Sensing for Industry and Environment Monitoring III, U. N. Singh, T. Itabe, and Z. Liu, Eds., International Society for Optical Engineering (SPIE Proceedings, Vol. 4893), 287-294.

$\longrightarrow, \ldots$, and S. X. Li, 2000: Wind measurements with a 355-nm molecular Doppler lidar. Opt. Lett., 25, 1231-1233.

Klett, J. D., 1985: Lidar inversion with variable backscatter/extinction ratios. Appl. Opt., 24, 1638-1643.

Leike, I., J. Streicher, C. Werner, V. Banakh, I. Smalikho, W. Wergen, and A. Cress, 2001: Virtual Doppler lidar instrument. J. Atmos. Oceanic Technol., 18, 1447-1456.

Li, Z., C. Lemmerz, U. Paffrath, O. Reitebuch, and B. Witschas, 2010: Airborne Doppler lidar investigation of the sea surface reflectance at the ultraviolet wavelength of $355 \mathrm{~nm}$. J. Atmos. Oceanic Technol., in press.

Marseille, G. J., and A. Stoffelen, 2003: Simulation of wind profiles from a space-borne Doppler wind lidar. Quart. J. Roy. Meteor. Soc., 129, 3079-3098.

McGill, M. J., W. D. Hart, J. A. McKay, and J. D. Spinhire, 1999: Modeling the performance of direct-detection Doppler lidar systems including cloud and solar background variability. Appl. Opt., 38, 6388-6397.

Menzies, R. T., 1986: Doppler lidar atmospheric wind sensors: a comparative performance evaluation for global measurement applications from earth orbit. Appl. Opt., 25, 2546-2553.

Noel, V., and K. Sassen, 2005: Study of planar ice crystal orientations in ice clouds from scanning polarization lidar observations. J. Appl. Meteor., 44, 653-664.

Paffrath, U., 2006: Performance assessment of the Aeolus Doppler wind lidar prototype. Ph. D. thesis, Technische Universität München and DLR Forschungsbericht, $137 \mathrm{pp}$.

Rees, D., and I. S. McDermid, 1990: Doppler lidar atmospheric wind sensor: Reevaluation of a 355-nm incoherent Doppler lidar. Appl. Opt., 29, 4133-4144.

Reitebuch, O., C. Lemmerz, E. Nagel, U. Paffrath, Y. Durand, M. Endemann, F. Fabre, and M. Chaloupy, 2009: The airborne demonstrator for the direct-detection Doppler wind lidar ALADIN on ADM-Aeolus. Part I: Instrument design and comparison to satellite instrument. J. Atmos. Oceanic Technol., 26, 2501-2515.

Schröder, T., C. Lemmerz, O. Reitebuch, M. Wirth, C. Wührer, and R. Treichel, 2007: Frequency jitter and spectral width of an injection-seeded Q-switched Nd:YAG laser for a Doppler wind lidar. Appl. Phys. B, 87, 437-444.

Stoffelen, A., and Coauthors, 2005: The Atmospheric Dynamics Mission for global wind field measurement. Bull. Amer. Meteor. Soc., 86, 73-87.

Tan, D. G. H., and Coauthors, 2008: The ADM-Aeolus wind retrieval algorithms. Tellus, 60A, 191-205.

Tao, Z., M. P. McCormick, and D. Wu, 2008: A comparison method for spaceborne and ground-based lidar and its application to the CALIPSO lidar. Appl. Phys., 91B, 639-644.

Vaughan, J. M., 2002: The Fabry-Perot Interferometer. Hilger, 583 pp. 
D. W. Brown, C. Nash, S. B. Alejandro, and G. G. Koenig, 1995: Atlantic atmospheric aerosol studies. 2. Compendium of airborne backscatter measurements at $10.6 \mu \mathrm{m}$. J. Geophys. Res., 100 (D1), 1043-1065.

Veldman, S. M., A. Stoffelen, G. J. Marseille, J. van Es, H. A. Knobhout, and E. A. Kuijpers, 1999: Lidar Performance Analysis Simulator (LIPAS). ESA Final Rep. CR(P)-4290, 50 pp.

Wandinger, U., 2003: Air mass modification process, EARLINET: A European aerosol research lidar network to establish an aerosol climatology. Max-Planck-Institute for Meteorology Rep. 348, 90 pp.
_ - and A. Ansmann, 2002: Experimental determination of the lidar overlap profile with Raman lidar. Appl. Opt., 41, 511514.

Winker, D. M., R. H. Couch, and M. P. McCormick, 1996: An overview of LITE: NASA's Lidar In-space Technology Experiment. Proc. IEEE, 84, 164-180.

Witschas, B., 2007: Characterisation of beam profile and frequency stability of an injection-seeded Nd:YAG laser for a Doppler wind lidar system. M.S. thesis, Department of Technical Physics, University of Applied Sciences Munich, $102 \mathrm{pp}$. 